\title{
Histopathologic analysis of appendectomy specimens
}

\author{
Shrestha $\mathrm{R}^{1}$, Ranabhat $\mathrm{SR}^{1}$, Tiwari $\mathrm{M}^{1}$ \\ ${ }^{1}$ Department of Pathology, Chitwan Medical College Teaching Hospital, Bharatpur, Nepal
}

\section{Keywords: \\ Appendectomy; Appendicitis; Histopathology}

\begin{abstract}
Background: Acute appendicitis is one of the common conditions requiring emergency surgery. A retrospective study was performed to determine various histopathological diagnoses, their demographics and the rates of perforated appendicitis, negative appendectomy and incidental appendectomy.
\end{abstract}

Materials and Methods: Histopathological records of resected appendices submitted to histopathology department Chitwan medical college teaching hospital over the period of 2 yrs from May, 2009 to April 2011 were reviewed retrospectively.

Results: Out of 930 specimens of appendix, appendicitis accounted for $88.8 \%$ with peak age incidence in the age group of 11 to $30 \mathrm{yrs}$ in both sexes. Histopathologic diagnoses included acute appendicitis (45.6\%), acute suppurative $(20.8 \%)$, gangrenous $(16.3 \%)$, perforated $(1.7 \%)$, resolving /recurrent/non specific chronic appendicitis $(2.5 \%)$, acute eosinophilic appendicitis $(1.2 \%)$, periappendicitis $(0.2 \%)$, and carcinoid tumour $(0.1 \%)$. Other important coexisting pathologies were parasitic infestation $(0.2 \%)$ and Meckel's diverticulum ( $0.2 \%)$. Negative appendectomy rate was $10.8 \%$ and three times more common in females with peak occurrence in the age group of 21-30 yrs. There were 10 cases of acute appendicitis in incidental appendectomies $(2.5 \%, 24$ cases $)$ with 7 times more common in females of age group of 31- 60 yrs.

Conclusion: There is a high incidence of appendicitis in adolescents and young adults in central south region of Nepal. Negative appendectomy is also very common in females. Incidental appendectomy in elderly females may have preventive value.

\section{INTRODUCTION}

Acute appendicitis is one of the most common surgical causes of acute abdomen. The lifetime risk for appendicitis is $7 \%$; commonly occurring in adolescents and young adults. ${ }^{1}$ The rate of acute appendicitis varies among countries. In USA, from 1979 to 1984 the annual appendicitis incidence rate in different parts of the country varied from 94 to 154

\section{Correspondence:}

Dr. Reshmi Shrestha, $M D$

Department of Pathology, Chitwan Medical College Teaching Hospital, Bharatpur, Nepal

E-mail:reshmishrestha@yahoo.com per $100,000 .^{2}$ Declining rates of acute appendicitis have been reported in the United States and Europe. ${ }^{3}$ In the UK, at North Tees Hospital, the incidence of acute appendicitis declined from about 100 to 52 per 100000 population from 1975 to $1991 .^{2}$ In developing countries, the incidence is increasing in most urban centers, probably due to adoption of western diet. ${ }^{4}$

Despite of advances in technology and imaging modalities, there is dilemma in the clinical diagnosis of acute appendicitis. Histopathological examination still remains the gold standard method for the confirmation of the 
appendicitis. Not only the pathologic diagnosis of acute inflammation, at times unusual findings such as incidental tumours noted in the appendix highlights the importance of the pathologic analyses of every single resected appendix.

This study aims to determine the various histologic diagnoses of all surgically removed appendices and to find out the age and sex related incidence of appendicitis, the perforation rate and the rate of negative and incidental appendectomies. In addition, we attempt to find out the possible causes of negative appendectomy.

\section{MATERIALS AND METHODS}

This was a retrospective study conducted in the pathology department at Chitwan Medical College Teaching hospital during the two years period from May, 2009 to April 2011. All the surgically resected appendices submitted to department of pathology were included in this study. All emergency appendectomies and interval appendectomies performed on clinically suspected appendicitis, and incidental appendectomies which were performed during other abdominal or pelvic surgeries were included. Relevant clinical data, gross findings and histopathologic diagnoses were retrieved from pathology record book and computer databases. Stastistical analysis was done by SPSS 16.00 .

Negative appendectomy was defined as one which is performed for a clinical diagnosis of acute appendicitis but in which the appendix is found to be normal on histopathological examination.

\section{RESULTS}

Total of 930 specimens of appendix were received in the histopathology department during the period of 2 years from 2009 to 2011 . Of total 930 appendectomies, there were 898 emergency appendectomy and 8 interval appendectomy performed for clinically suspicious appendicitis (906 cases). The remaining 24 cases were elective or incidental appendectomy done for other primary abdominal or pelvic pathology.

Total $817(88.8 \%)$ cases were found to have histologically proven appendicitis. This accounted for overall incidence of $20 \%$ of appendicitis among the total surgical specimens $(n=4069)$. There were $387(47.4 \%)$ males and $430(52.6 \%)$ females among 817 cases of appendicitis with the male: female ratio of $1: 1.1$. The mean age for female was $30.5 \pm 15.08$ yrs with a range of 2 to 84 yrs and the mean age for male was $26.6 \pm 15.4$ yrs with a range of 1 to $75 \mathrm{yrs}$. The peak age incidence of appendicitis was found in the age group of 11 to 30 years. However, peak age incidence for males was 11 to 20 and 20 to 30 yrs for females. More than $80 \%$ cases of appendicitis occurred below the age of 40 years.
All acutely inflamed appendices had peak incidence in the age group of 11 to $30 \mathrm{yrs}$. Chronic/ recurrent/ resolving and eosinophilic appendicitis were commonly seen in the age group of 21 to 40 yrs. Sex distribution of inflamed appendices at various stages is shown in Table 1 .

Perforation rate was $1.9 \%$ (16 out of 817 cases ). Perforated appendicitis was seen more commonly in females at the age interval of 11-30 yrs. The rate in adults in the age group of 15 to 50 years was significantly different $(p=<0.05)$ when compared to ages below $15 \mathrm{yrs}$ and $>50 \mathrm{yrs}$.

Parasite was present in 2 histologically proven appendicitis of which, one had luminal parasite (unidentified species) associated with acute appendicitis. Another was a case of chronic appendicitis with suspected parasitic infestation due to presence of foreign body reaction associated with transmural eosinophilic infiltration. One carcinoid tumour $(0.1 \%)$ was diagnosed incidentally in a patient clinically suspected as appendicitis. The tumour was found at the tip of the appendix measuring $1 \mathrm{~cm}$ in length with no mesoappendiceal or distant metastasis and thus the patient was kept under close follow up without further surgical procedure.

Some of the clinically suspicious appendicitis which was proven to be appendicitis later by microscopic examination had other associated histologic findings. These included endosalpingiosis of appendix, broad ligament cyst, mesenteric cyst, villotubular adenoma of Meckel's diverticulum.

\section{Negative appendectomy}

The rate of negative appendectomies was 10.8\% (98 out of 906 cases). It was significantly higher in female patients ( $\mathrm{P}=0.007)$ and in the $21-30$ year age group $(\mathrm{P}=0.02)$ with the female: male ratio of 3.08:1. Primary cause of acute abdominal pain could be found in few negative appendectomies and is shown in Table 2.

\section{Incidental appendectomy}

There were total 24 cases $(2.5 \%)$ of incidental appendectomy of which 3 were males and 21 were females. The most common primary surgery was total abdominal hysterectomy with bilateral salpingo-oo phorectomy (16 cases) followed by oophorectomy with or without adenectomy (3 cases), GI surgery (4 cases; 1 female, 3 males) and one emergency exploratory laparatomy ( 1 female). The age ranged from 7 to 70 years and the peak age interval was 31 to 60years. Of total 24 cases, 10 had histologic diagnosis of acute appendicitis; 8 of them were females and remaining 2 were males. The Table 3 shows the primary diagnoses associated with appendicitis in incidental appendectomy. Acute appendicitis was seen between the age interval of 21 to 80 years with increased frequency in the age group 41 to 60 years. Six out 
Table 1: The Distribution of Histopathologic stages of appendicitis by Sex

\begin{tabular}{llll}
\hline Histologic stages & Female $(\mathbf{n}=\mathbf{4 2 8})$ & Male $(\mathbf{n}=\mathbf{3 8 9})$ & Total $(\mathbf{n}=\mathbf{8 1 7})$ \\
\hline Acute appendicitis & $57.5 \%(246)$ & $46.0 \%(179)$ & $52.0 \%(425)$ \\
Acute suppurative appendicitis & $18.7 \%(80)$ & $28.0 \%(109)$ & $23.2 \%(189)$ \\
Acute gangrenous appendicitis & $16.1 \%(69)$ & $21.4 \%(83)$ & $18.7 \%(152)$ \\
Perforated appendicitis & $3.0 \%(13)$ & $0.8 \%(3)$ & $1.9 \%(16)$ \\
Eosinophilic appendicitis & $2.1 \%(9)$ & $0.5 \%(2)$ & $1.3 \%(11)$ \\
Chronic/ resolving/recurrent appendicitis & $2.6 \%(11)$ & $3.3 \%(13)$ & $2.9 \%(24)$ \\
\hline Pearson chi square test: $27.385 \quad P=0.001$ & & &
\end{tabular}

Table 2: Other pathologic diagnoses in negative appendectomy

\begin{tabular}{lc}
\hline Diagnoses & No of cases \\
\hline Follicular cyst & 1 \\
Twisted ovarian cyst & 1 \\
$\begin{array}{l}\text { Haemorrhagic endometriotic cyst } \\
\text { with periappendicitis }\end{array}$ & 8 \\
\hline Periappendicitis & 1 \\
Meckel's diverticulitis & 1 \\
Fimbrial hematoma & 1 \\
\hline
\end{tabular}

of 10 cases of incidental appendectomy that were associated with appendicitis, had features of peritonitis. Remaining 4 cases of positive incidental appendectomy were associated with adenomyosis, fibroid and abortion.

\section{DISCUSSION}

Acute appendicitis has been the most common surgical emergency for a number of decades and the appendectomy is the most frequently performed abdominal operation. In the western world ${ }^{5}$, accute appendicitis accounts for about $40 \%$ of all surgical emergencies. It is rare in Asian and African subcontinent; however recent literature reviews show that there is an increase in incidence of appendicitis in African countries with adoption of western life style and diets. ${ }^{4}$ Similarly in South Korea, epidemiological study done by Lee et al, from 2005 to 2007, showed an overall incidence of appendicitis and appendectomy of 22.71 and 13.56 per 10,000 population per year, respectively which was found to be higher than that of western countries, i.e. 7.5 to 12.0 per 10,000 population per year. $^{6}$

Our observation also showed the higher frequency of appendectomy of $22.8 \%$ and similarly a high incidence of appendicitis accounting to $20 \%$. The other studies done in Nepal showed a variable incidence rate of appendicitis. Khan et $\mathrm{al}^{7}$, from Nepalgunj, reported acute appendicitis to be the most common cause of emergency laparatomy showing incidence of $26 \%$. However, there was a low incidence rate of acute appendicitis of only $7.46 \%$ in the study conducted by makaju et al. ${ }^{8}$
The incidence of appendicitis varies substantially by country, geographical region, race, socioeconomic status, dietary habits, hygiene, sex, age and season. ${ }^{4}$ The high incidence of appendicitis, particularly in this region could be explained by the improvement in socioeconomic status that would directly affect the dietary habits with high intake of meat, increased health awareness and an easy access to the hospital.

Age incidence of appendicitis were higher in the second and third decade, about $80 \%$ of appendicitis occurring below 40 years of age in concordance with various studies.4,9,10 In contrast to other studies ${ }^{4,5,10}$, which showed male to female ratio ranging from 1.1 to $2.9: 1$, we had slightly female preponderance with the female male ratio of 1.1:1. However, it was observed that males at adolescent age group had higher incidence than the females similar to other studies. Migration of majority of male adults to foreign countries in search of work has been a trend here and might have disturbed the overall population structure. Therefore, this could be the reason for the overall higher incidence of acute appendicitis in females than males.

Maximum frequency of histologic diagnoses was acute appendicitis (45.6\%) followed by acute suppurative $(20.8 \%)$ and gangrenous appendicitis (16.3\%) similar to other study done by zulfikar et al. ${ }^{11}$

Nabipour et $\mathrm{al}^{10}$ found poor positive correlation between the histologic stage and age and sex incidence. In the present study, the age incidence followed a similar pattern in all acutely inflamed appendicitis occurring in young adults (i.e. the age group of 10 to $30 \mathrm{yrs}$ ). However, sex incidence was higher in males in acute suppurative and acute gangrenous appendicitis and it was higher in females in acute appendicitis and perforated appendicitis $(\mathrm{p}=0.01)$.

Eosinophilic appendicitis and chronic/ recurrent/ resolving appendicitis were more common in females and in slightly older age group. The frequency of eosinophilic appendicitis was $1.2 \%$ in our study which was closer to the incidence of $1 \%$, found by Park et al. ${ }^{12}$ The diagnosis of chronic / recurrent / resolving appendicitis is still controversial; and its existence has been debated. Some authors postulated that chronic or recurrent pelvic pain may be, to some extent, attributed to a chronically inflamed appendix; and, when 
Table 3: Primary pathologic diagnoses associated with acute appendicitis in incidental appendectomy

\begin{tabular}{|c|c|c|c|}
\hline Diagnoses & Age & Sex & No. of cases \\
\hline \multicolumn{4}{|l|}{ Diseases associated with peritonitis: } \\
\hline Perforated gastric ulcer & 35 & M & 1 \\
\hline TB peritonitis & 58 & M & 1 \\
\hline Colonic adenocarcinoma & 52 & M & 1 \\
\hline Tuboovarian abscess & 21 & $\mathrm{~F}$ & 1 \\
\hline Borderline serous cyst tumour with positive ascitic fluid & 65 & $\mathrm{~F}$ & 1 \\
\hline Acute salpingitis with chronic endometritis & 71 & $\mathrm{~F}$ & 1 \\
\hline \multicolumn{4}{|l|}{ Diseases without associated peritonitis: } \\
\hline Adenomyosis & 46 & $\mathrm{~F}$ & 1 \\
\hline Fibroid with complex endometrial hyperplasia & 41,55 & $\mathrm{~F}$ & 2 \\
\hline Retained product of conception & 25 & $\mathrm{~F}$ & 1 \\
\hline Total & & & 10 \\
\hline
\end{tabular}

removed in an otherwise anatomically normal pelvis, can reduce pain in one half of the patients. ${ }^{13,14}$ In our series, it was found to be $2.5 \%$ in the young and older adults, while it was still higher in other study. ${ }^{14}$ Therefore, recurrent abdominal pain should not be overlooked and a high index of suspicion of appendicitis is essential to avoid repeated unnecessary admissions.

The perforation rate was low $(1.9 \%)$ in our study similar to that shown by other studies. ${ }^{10,15}$ Number of series ${ }^{3,5,6,9,16}$ however had quite higher values, ranging from 8.3 to $23.2 \%$. We also observed that the age incidence of the perforated appendicitis was quite different, in comparison to other studies. We had a higher incidence of perforation rate in the age group of 11- 30 yrs when compared to that of age below 15 yrs and above 50yrs ( $p$ value $<0.5$ ). Most of these studies ${ }^{6,14,15}$ showed the extremes of age with higher perforation rate. The decrease frequency might be due to early visit in the hospital in most of the cases and the prompt decision to operate for suspected appendicitis by the surgeons.

Parasitic infestation is thought to be one of the causes of luminal obstruction of appendix leading to appendicitis. Several studies have found luminal parasites in the appendix associated with or without appendicitis in the range of 0.3 to 3.15\%.16-18 Commonly found parasites include enterobius vermicularis and schistosoma species. In our study, only 2 cases had parasitic infestation $(0.2 \%)$, out of which one had unidentified parasite in the lumen of chronically inflamed appendix and another was suspicious due to presence of foreign body reaction and transmural eosinophilic infiltration.

There was only one case of incidental carcinoid tumour $(0.1 \%)$. The literature review13,15,18-,20 showed the incidence of carcinoid tumour ranging from $0.1 \%$ to $1.05 \%$ mostly found incidentally during microscopic examination. In the present study, the tumour was not associated with acute inflammation of the appendix and the abdominal pain could be explained due to the elaboration of inflammatory mediators. $^{12}$

\section{Negative appendectomy}

In our study, negative appendectomy rate of $10.6 \%$ falls within the acceptable range of 10 to $20 \%{ }^{6}$ Various studies $^{10,11,15,18}$, has shown a wide range of rate that falls between 6.1 to $34.2 \%$, with higher values in females. The present study showed females having higher rates of negative appendectomy frequently occurring within the younger age group of 11 to $30 \mathrm{yrs}$. Edino et $\mathrm{al}^{5}$ and Marudanayagam et al $^{15}$ also presented the similar finding which showed a high incidence in the age group of 10- 19 yrs and 11- 30 yrs respectively. Similar to other studies ${ }^{15,16}$, we found other pathologies such as ovarian cyst, Meckel's diverticulitis and periappendicitis as the causes of acute abdominal pain in negative appendectomy.

Therefore, especially in females, other causes of abdominal pain should be searched for if the appendix appears normal during operation. The use of diagnostic laparoscopy followed by appendectomy if necessary in fertile female patients was found to reduce the rate of negative appendicectomy several fold. ${ }^{15,21}$ However, this is also true that most of the negative appendectomy cases are relieved of pain after surgery. Wang et $\mathrm{al}^{22}$ demonstrated that TNF- $\alpha$ ) and interleukin-2 expression are sensitive markers of inflammation in appendicitis. A significant number of histologically normal appendix specimens (22.5\%) showed increased cytokine expression, indicating an inflammatory reaction. Therefore, normal-looking appendices have a $22 \%$ chance of being inflamed on further sophisticated investigations.

\section{Incidental appendectomy}

The rate of incidental appendectomy was only $2.5 \%$ in our study. One series ${ }^{23}$ demonstrated the incidence of incidental 
appendectomy 1.13/1,000 persons per year. Similar to other studies $^{20,24}$, incidental appendectomy was 7 times more common in females undergoing pelvic surgery above the age of 30 years. The removal of appendix was justified in $37.5 \%$ of incidental appendectomy showing positivity for acute appendicitis. Of total 10 cases, coexisting acute appendicitis in six cases could be explained by virtue of peritonitis associated with primary disease, leading to appendicitis, as a result of contiguous spread of inflammation to the appendix. However, no plausible reason could be found in the rest four cases of acute appendicitis which were associated with primary gynaecologic diseases. These 4 cases $(16.6 \%, n=24$ cases $)$ of acute appendicitis were truly incidental finding detected commonly in the age group of 41- $60 \mathrm{yrs}$ and, thus prevented the further need of appendectomy. The studies that evaluated the mortality and morbidity of incidental appendectomy associated with appendicitis were found to be insignificant and thus the authors have advocated incidental appendectomy in all abdominal or pelvic surgeries. ${ }^{14,22}$ Therefore, the practice of incidental appendectomy in uncomplicated abdominal or pelvic surgery might decrease the rates of mortality and morbidity associated with appendicitis and appendectomy in the elderly.

\section{CONCLUSION}

The incidence of appendicitis is high, in the second and third decades of life and slightly higher in females. Low perforation rate indicates a better prospective regarding morbidity and mortality. Findings of pelvic pathologies in females, such as ovarian cysts, in negative appendectomy emphasize the usefulness of the laparascopic surgery that would help to minimize negative appendectomy rate. Incidental appendectomy may have preventive value in elderly females. Finally, an unusual finding such as carcinoid tumour in the clinically suspected acute appendicitis reflects the value of histological examination of every resected appendix, the presence of which would alter the further management. Incidental appendectomy in elderly females may have preventive value.

\section{REFERENCE}

1. Turner JR. The Gastrointestinal tract, In: Kumar,Abbas,Fausto (eds). Robins and Cotran Pathologic basis of disease. 8th edn. Saunders: Philadelphia; 2010. pp870-1.

2. Walker AR, Segal I. Appendicitis: an African perspective. J R Soc Med 1995; 88:616-9.

3. Al-Omran M, Mamdani MM, McLeod RS. Epidemiologic features of acute appendicitis in Ontario, Canada. Can J Surg 2003;46:263-8.

4. Oguntola AS, Adeoti ML, Oyemolade TA. Appendicitis: Trends in incidence, age, sex, and seasonal variations in South-Western Nigeria. Ann Afr Med 2010;9:213-7.
5. Edino ST, Mohammed AZ, Ochicha O, Anumah M. Appendicitis in Kano, Nigeria: A 5 year review of pattern, morbidity and mortality. Ann Afr Med 2004;3:38-41.

6. Lee JH, Park YS, Choi JS. The epidemiology of appendicitis and appendectomy in South Korea: National Registry Data. J Epidemiol 2010;20:97-105.

7. Khan S, Khan IU, Aslam S, Haque A. Retrospective analysis of abdominal surgeries at Nepalgunj Medical College (NGMC), Nepalgunj, Nepal: 2 year's experience. KUMJ 2004;2:336-43.

8. Makaju R, Mohammad A, Shakya A. Acute appendicitis: Analysis of 518 histopathologically diagnosed cases at the Kathmandu University Hospital, Nepal. KUMJ 2010;8:227-30.

9. Noudeh YJ, Sadigh N, Ahmadnia AY. Epidemiologic features, seasonal variations and false positive rate of acute appendicitis in Shahr-e-Rey, Tehran. Int J Surg 2007;5:95-8.

10. Nabipour F. Histopathological feature of acute appendicitis in Kerman-Iran from 1997 to 2003. Am J Env Sci 2005;1:130-2.

11. Zulfikar I, Khanzada TW, Sushel C, Samad A. Review of the pathologic diagnoses of appendectomy specimens. Ann King Edward Med Univ 2009;15:168-70.

12. Park CS, Chang MS, Park IA, Kim YI, Choe G. Pathologic analysis of 2159 cases of appendix. Korean J Pathol 2000;34:39-49.

13. Salom EM, Schey D, Penalver $M$ et al. The safety of incidental appendectomy at the time of abdominal hysterectomy. Am J Obstet Gynecol 2003;189:1563-7

14. Chang SKY, Chan P. Recurrent appendicitis as a cause of recurrent right iliac fossa pain. Singapore Med J 2004;45:6-8.

15. Korner H, Sondenaa Karl, Soreide JA et al. Incidence of acute nonperforated and perforated appendicitis: Age-specific and sexspecific analysis. World J. Surg 1997;21:313-7.

16. Marudanayagam R, Williams GT, Rees BI. Review of the pathological results of 2660 appendicectomy specimens. J Gastroenterol 2006;41:745-9.

17. Aydin O. Incidental parasitic infestations in surgically removed appendices: a retrospective analysis. Diagn Pathol 2007;2:16.

18. Duzgun AP, Moran M, Uzun $\mathrm{S}$ et al. Unusual findings in appendectomy specimens: Evaluation of 2458 cases and review of the literature. Indian J Surg 2004;66:221-6.

19. Ojo OS, Udeh SC, Odesanmi WO. Review of the histopathological findings in appendices removed for acute appendicitis in Nigerians. J R Coll Surg Edinb 1991;36:245-8.

20. Jones AE, Phillips AW, Jarvis JR, Sargen K. The value of routine histopathological examination of appendicectomy specimens. BMC Surg 2007;10:7.

21. Engin O, Calik B, Yildirim M, Coskun A, Coskun GA. Gynecologic pathologies in our appendectomy series and literature review. J Korean Surg Soc 2011;80:267-71.

22. Wang Y, Reen DJ, Puri P. Is a histologically normal appendix following emergency appendicectomy alway normal? Lancet 1996;20:1076-9.

23. Sugimoto T, Edwards D. Incidence and costs of incidental appendectomy as a preventive measure. Am J Public Health $1987 ; 77: 471-5$

24. Snyder TE, Selanders JR. Incidental appendectomy-Yes or No? A retrospective case study and review of the literature. Infect Dis Obstet Gyneco 1998;6:30-7. 